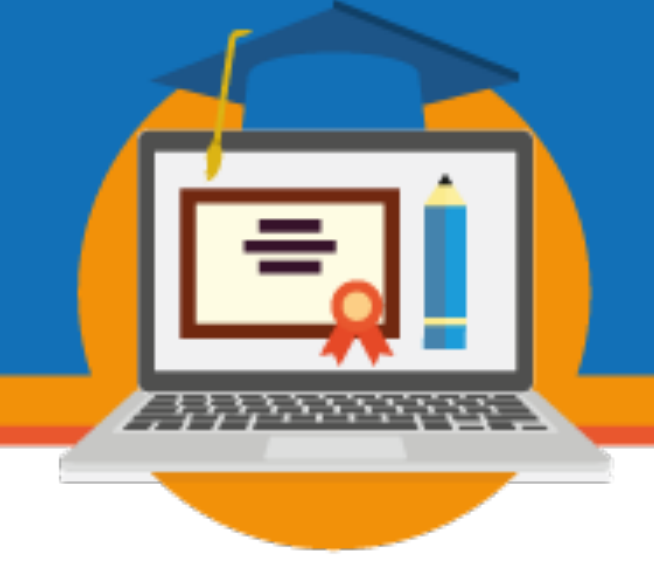

\title{
LETRAMENTOS DIGITAIS DE PROFESSORAS EM FORMAÇÃO CONTINUADA: MEDIAÇÕES COM TECNOLOGIAS E LITERATURA INFANTIL
}

\author{
Mariana Hanae Nascimento Hayashi (PPGE/UFMT) \\ mah_hayashi@hotmail.com
}

\author{
Marta da Conceição de Paula (PPGE/UFMT) \\ profmarta.maiseducacao@gmail.com
}

\section{Terezinha Fernandes (PPGE/UFMT)}

terezinha.ufmt@gmail.com

Eixo 06: Tecnologias e mediações pedagógicas

\begin{abstract}
Resumo:
A análise da experiência apresentada teve como objetivo refletir sobre a formação continuada com o uso de tecnologias desenvolvida pela Secretaria Municipal de Educação do município de Cuiabá - MT e seu alcance na mediação ao desenvolvimento de letramentos digitais dos professores participantes. $\mathrm{O}$ estudo circunscreve-se nas pesquisas de cunho qualitativo, com pesquisa bibliográfica e análise de uma experiência prática. Utilizamos os conceitos de Cultura Digital, Tecnologias Digitais (TD), Letramentos Digitais (LD), Mediação, Literatura lnfantil (LI), Formação continuada (FC) e outros. Os resultados obtidos demonstram que a FC provocou o desenvolvimento de diversos LD e estes podem ter alcances maiores com a continuidade de práticas formativas com TD oferecidas aos professores.
\end{abstract}

Palavras-chave: Formação continuada. Letramentos digitais. Tecnologias.

\section{Introdução}

Estamos imersos na cultura digital com a multiplicação de acesso e produção de informação. Diante deste cenário, pensar a educação e os elementos que constituem a Formação Continuada de Professores (FC) e as mediações pedagógicas com o uso de Tecnologias Digitais (TD) torna-se cada vez mais urgente. 


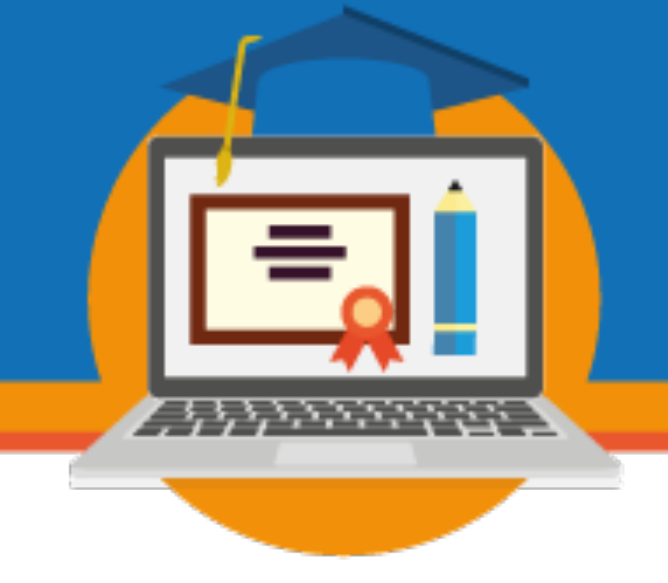

Neste relato de experiência objetivamos refletir sobre a formação continuada com o uso de tecnologias desenvolvida pela Secretaria Municipal de Educação do município de Cuiabá MT e seu alcance na mediação ao desenvolvimento de letramentos digitais (LD) dos professores participantes.

Buscamos analisar a FC na oficina "Letramento Digital: a sequência didática e o uso de tecnologia", realizada pela Secretaria Municipal de Educação (SME) Cuiabá - Mato Grosso dialogando com autores que abordam o contexto da Cultura Digital, Tecnologias Digitais (TD), Letramentos Digitais (LD) e Formação Continuada (FC) de Professores, por meio de pesquisa bibliográfica como recorte de duas pesquisas mais amplas realizadas no Mestrado do Programa de Pós-graduação em Educação, na Universidade Federal do Mato Grosso (UFMT).

Apresentamos as reflexões deste relato de experiência em quatro partes, na primeira o referencial teórico dos conceitos abordados, na segunda o desenvolvimento da Formação continuada de professores "Letramento Digital: a sequência didática e o uso de tecnologia" no município de Cuiabá - MT, na terceira resultados, análises e discussões e na quarta as conclusões com os aspectos que julgamos importante ressaltar da FC e possibilidades de mobilização de LD para esta e outras formações de professores.

\section{Referencial Teórico}

$\mathrm{Na}$ intenção de refletir sobre a experiência vivenciada na formação continuada desenvolvida pela Secretaria Municipal de Educação do município de Cuiabá - MT e seu alcance na mediação ao desenvolvimento de letramentos digitais das professoras' participantes, discutimos os conceitos de cultura digital (CD), tecnologias digitais (TD), letramentos digitais (LD), mediação, formação continuada (FC) e literatura lnfantil (LI), de acordo com a perspectiva adotada neste estudo.

${ }^{1}$ Todas as participantes a edição do curso analisada eram mulheres, por isso usaremos professoras, no feminino.

III SEMINÁRIO DE EDUCAÇÃO A DISTÂNCIA 
Considerando que vivemos contemporaneamente imersos a uma cultura permeada por dispositivos tecnológicos em nosso cotidiano do trabalho, para entretenimento e lazer e como fonte de pesquisa e informação. A esse tempo marcado e atravessado pelas tecnologias digitais situamos como cultura digital "[...] uma cultura em constituição que denota um constante 'porvir', dadas as possibilidades de compartilhamento, remixagens, mesclas e hibridizações que refletem novas e outras maneiras de construção e socialização de conhecimento" (SILVA e ALONSO, 2018 p.109).

Há diversos modos de conceituar cultura digital, Lucena (2016) por exemplo destaca que "O que estamos denominando aqui de cultura digital ou cibercultura são as formas de usos e apropriações dos espaços virtuais feitos pelos sujeitos culturais" (LUCENA, 2016, p. 281). Nesse sentido, é importante ter claro que a cultura digital é um fenômeno historicamente condicionado e continua em mudança e transformação.

A discussão sobre o cenário cultural em que estamos inseridos traz a tona o que concebemos como Tecnologias Digitais (TD), ou seja, os artefatos culturais que são produzidos no contexto desta cultura. Ao definir a cultura como um processo Santaella (2010) o segmenta em seis eras culturais - oral, escrita, impressa, de massas, das mídias e digital - que "estão pautadas na convicção de que os meios de comunicação [...] são capazes não só de moldar o pensamento e a sensibilidade dos seres humanos, mas também de produzir o surgimento de novos ambientes socioculturais" (SANTAELLA, 2010, p.13). As TD são definidas por "produções culturais de determinada sociedade e seu caráter histórico, sendo as tecnologias elementos centrais da produção e reprodução de cultura" (HEINSFELD e PISCHETOLA, 2017, p. 1354).

Neste contexto cultural e tecnológico, que permite outras maneiras de construção e socialização de conhecimentos, percebemos novas práticas com tecnologias, fundamentais para a desenvolvimento do sujeito enquanto participante ativo. Dentre tais práticas, temos os Letramentos Digitais (LD), que são "práticas contextualizadas social, cultural e historicamente, consoantes a cultura atual, a cibercultura, e exige a abertura para a formação do pensamento, da crítica e da autonomia dos sujeitos" (SOUZA, 2016, p. 214).

\section{SEMINÁRIO DE EDUCAÇÃO A DISTÂNCIA}




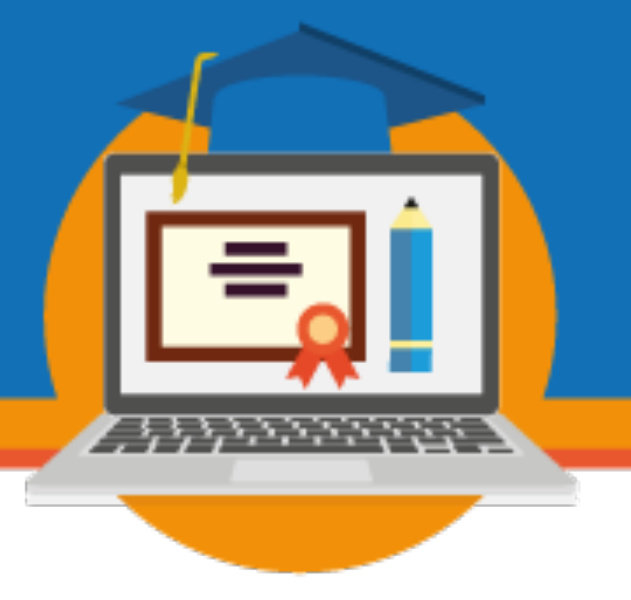

sujeitos em atividades cotidianas ou em processos como da FC, que em conjunto podem mediar o desenvolvimento ou a mobilização de letramentos nos sujeitos.

\section{A Formação continuada de professores "Letramento Digital: a sequência didática e o uso de tecnologia" no município de Cuiabá - MT}

As experiências na formação continuada com o uso da lousa digital ${ }^{2}$ para duas das autoras deste relato, iniciaram no ano de 2017 a oficina intitulada "Letramento Digital: a sequência didática e o uso de tecnologia ${ }^{3}$, realizada pela Secretaria Municipal de Educação (SME) Cuiabá, ministrada por três professores. Esta formação continuada teve uma carga horária de 40 horas, destinada a professores e professoras das unidades escolares de Cuiabá/Mato Grosso. Os encontros aconteciam de forma intercalada, a cada duas semanas, nos momentos de hora atividade dos professores e o objetivo geral da formação era promover o contato e a ampliação da prática dos profissionais da educação na utilização de "ferramentas tecnológicas" "disponíveis e acessíveis aos professores. Os objetivos específicos da formação foram: a) Conhecer e aprofundar os conhecimentos na ferramenta Power Point (sic); b) Criar e formatar apresentação de slides; c) Inserir e formatar imagens, giff' $S^{6}$ (sic), vídeos, animações e outros utilizando a internet; d) Criar Quiz' . O foco da formação era desenvolver uma sequência

\footnotetext{
${ }^{2}$ Lousa Digital é um dispositivo leve e portátil, interativo, que possui teclado, mouse, portas USB, portas de Rede, leitor de DVD e projetor multimídia. Foi concebido e desenvolvido por Universidades Federais adquiridos por meio de adesão ao pregão realizado pelo Fundo Nacional de Desenvolvimento da Educação (FNDE). Os equipamentos foram distribuídos às escolas brasileiras através do Programa Nacional de Formação Continuada em Tecnologia Educacional (ProInfo Integrado).

${ }^{3}$ A opção por "ferramentas tecnológicas" para tratar de tecnologias digitais no título e no objetivo da formação continuada em análise provavelmente coaduna-se com as orientações teóricas adotadas. Neste estudo estamos concebendo-as como dispositivos ou artefatos tecnológicos produzidos no contexto de determinada cultura, na atualidade a cultura digital.

${ }^{4}$ Originalmente no documento de formação consta "ferramentas tecnológicas", entretanto percebemos estas como artefatos culturais ligados à nossa sociedade e cultura.

${ }^{5}$ PowerPoint é um programa proprietário de criação e exibição de apresentações gráficas da empresa Microsoft. Utiliza-se de imagens, sons, textos e vídeos para alcançar seus objetivos.

${ }^{6}$ GIF (Graphics Interchange Format ou formato de intercâmbio de gráficos) é um formato de imagem utilizada em meios digitais que compacta várias cenas com a intenção de exibir movimentos.

${ }^{7} \mathrm{Na}$ concepção da formação, o quiz é um jogo de questionários que tem como objetivo fazer uma avaliação dos conhecimentos sobre determinado assunto.
}

\section{SEMINÁRIO DE EDUCAÇÃO A DISTÂNCIA}




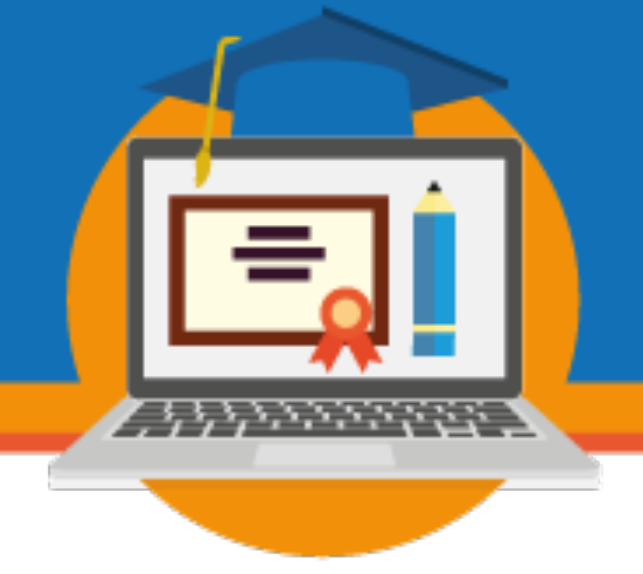

didática baseada em um livro de literatura infantil e jogo do tipo quiz a ser projetado na lousa digital.

A formação continuada foi dividida em três etapas, sendo a primeira de apresentação do projeto de formação, bem como a sequência didática a ser desenvolvida como produto. $\mathrm{Na}$ segunda etapa foi trabalhado os conteúdos: Iniciando o Power Point (sic); Conceitos básicos; Layout de Slides (Layout pré definido); Inserir Slides; Inserir Caixa de Texto; Formatar Texto; Formatar Caixa de Texto; Design; Formatar Plano de Fundo; Inserir Imagem; Formatar Imagem; Efeitos de; Transição de Slides; Animações; Inserir Vídeos e Sons; Criar Quiz Botões de Ação. A terceira etapa foi a apresentação das sequências didáticas desenvolvidas pelas professoras cursistas.

A partir de atividades e metodológias diversificadas, a formação trouxe um novo olhar enriquecendo as ações pedagógicas, oportunizando novos caminhos na construção do conhecimento dos participantes e no desenvolvimento de letramentos digitais necessários à prática de ensino e aprendizagem na escola.

A FC proporcionou a possibilidade de trabalho com a literatura infantil e a contação de história, fazendo a integração entre o uso do livro físico e a projeção do mesmo na lousa digital para melhor visualização das imagens. É esta experiência que iremos analisar e discutir no próximo item.

\section{Resultados, análises e discussões}

Durante o curso foram apresentados exemplos de histórias e jogos a serem produzidos com o PowerPoint e projetados na lousa digital. Na segunda etapa cada professora escolheu um poema ou texto para recriar em forma de jogo do tipo Quiz.

A partir das histórias trabalhadas no curso eram desenvolvidas questões acerca das personagens e sobre o enredo da história e era oferecido algumas respostas e dentre elas, apenas uma seria a correta. Ao clicar na resposta certa ou errada, o próximo quadro a aparecer na lousa

\section{SEMINÁRIO DE EDUCAÇÃO A DISTÂNCIA}




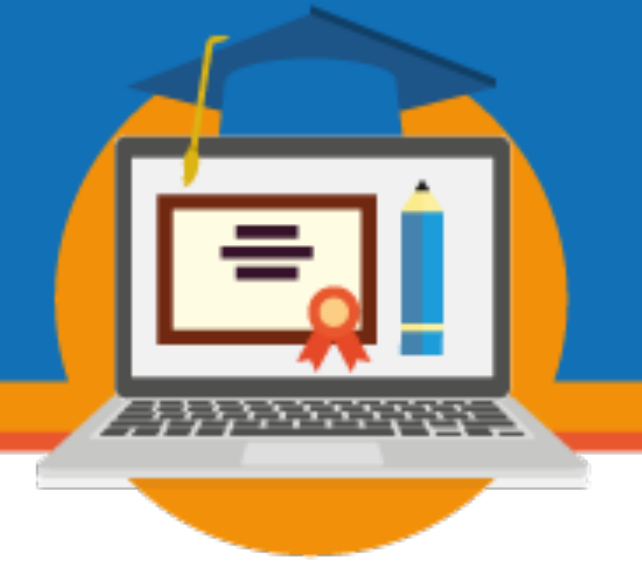

digital era o de confirmação, dizendo se o jogador acertou ou se devia tentar novamente e assim prosseguir para a próxima questão até terminar o jogo.

Apesar dos exemplos exibidos na formação serem de livros infantis ${ }^{8}$, os formadores destacaram que as formas poderiam ser variadas, com vídeos, poemas e textos, sendo os dois últimos indicados a serem utilizados nas atividades da FC por conta do tempo que demandaria para a leitura das histórias e da quantidade de professoras cursistas a apresentarem os resultados na culminância. Das histórias utilizadas nos jogos durante o curso apresentamos a obra a seguir para discutir os modos como este foi trabalhado durante a formação.

Iniciamos a formação Continuada de Professores com um exemplo de atividade interativa com o livro infantil: Até as princesas soltam pum, de Illan Brenman; Ionil Zilberman, conforme imagem 1 abaixo:

- Capa da obra "Até as princesas soltam pum"

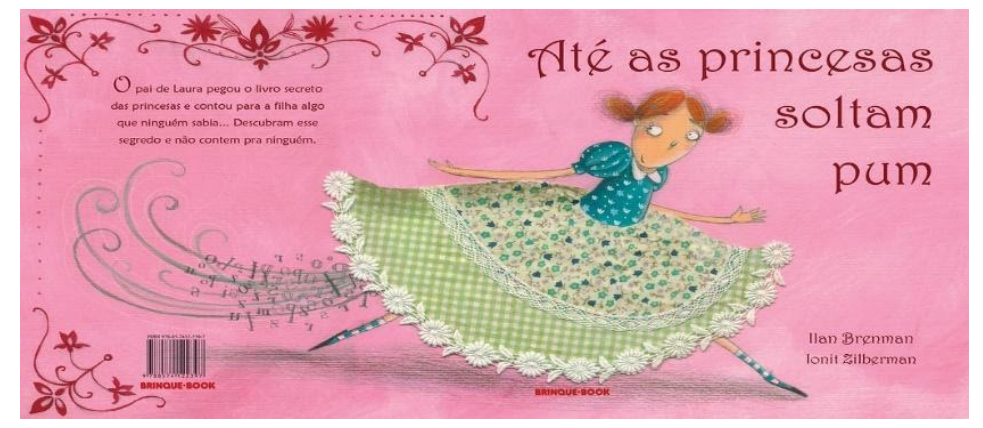

Fonte: https://www.flickr.com/photos/solrenno/5743398221/

${ }^{8}$ Por exemplo as histórias "O sanduíche de Maricota" de Avelino Guedes e “Até as princesas soltam pum” de Ilan Brenman; Ionit Zilberman. 

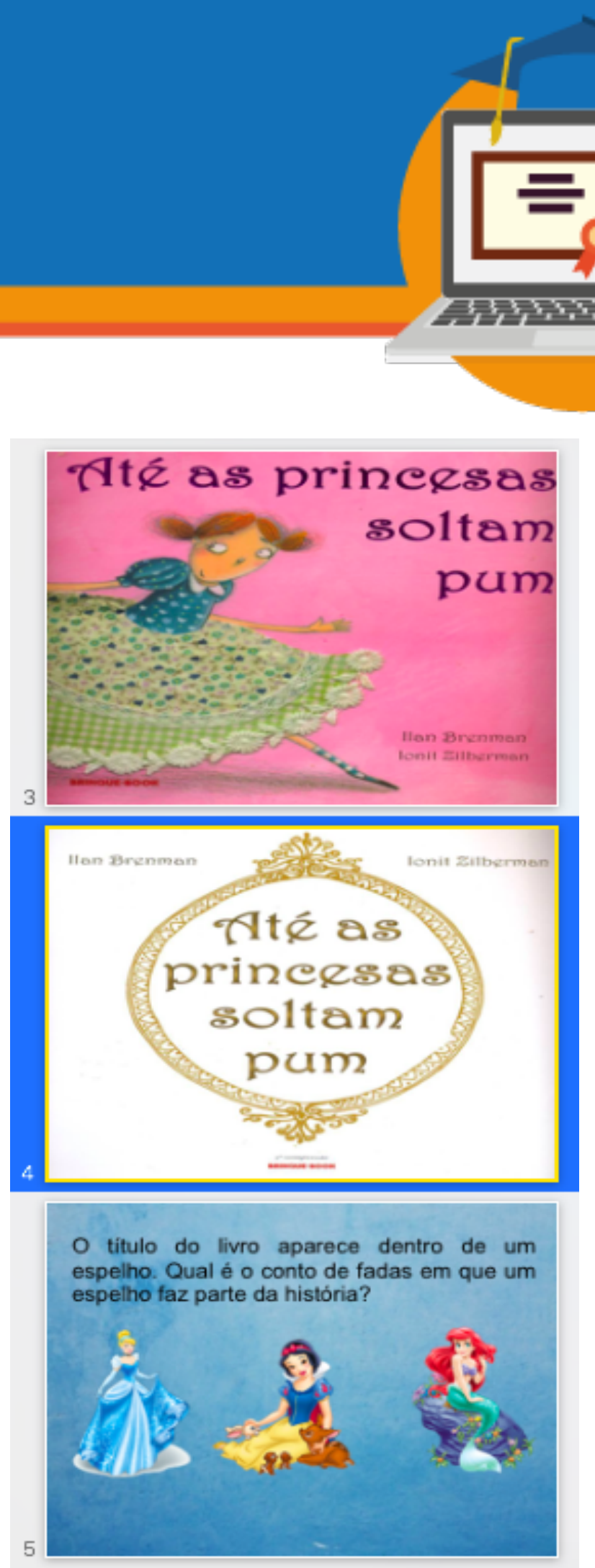

Imagens: slides "Até as princesas soltam pum"

Fonte: atividade trabalhada na formação continuada.

No slide 4 exploramos a capa do livro, com alguns questionamentos, entre eles "qual história vamos conhecer neste livro?". Buscando conjecturar as possíveis respostas das crianças

\section{SEMINÁRIO DE EDUCAÇÃO A DISTÂNCIA}

Diálogos sobre EaD e uso das TDIC na educação: regulamentação em tempos recentes 3 a 6 de novembro de 2020 - Brasília/DF - Online 


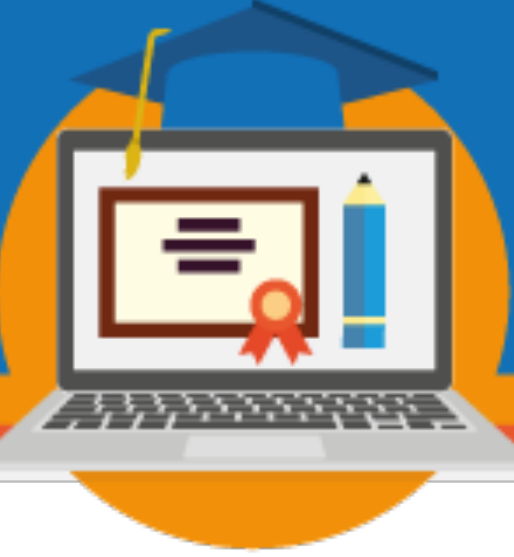

e quais perguntas ou imagens poderíamos inserir no slide para despertar interesse e curiosidade na leitura.

Os formadores apresentaram o slide 5 com a seguinte pergunta: $O$ título do livro aparece dentro de um espelho. Qual é o conto de fadas que um espelho faz parte da história? Havia a figura de três princesas para que pudéssemos responder entre elas: Cinderela, Branca de Neve, e Ariel. 


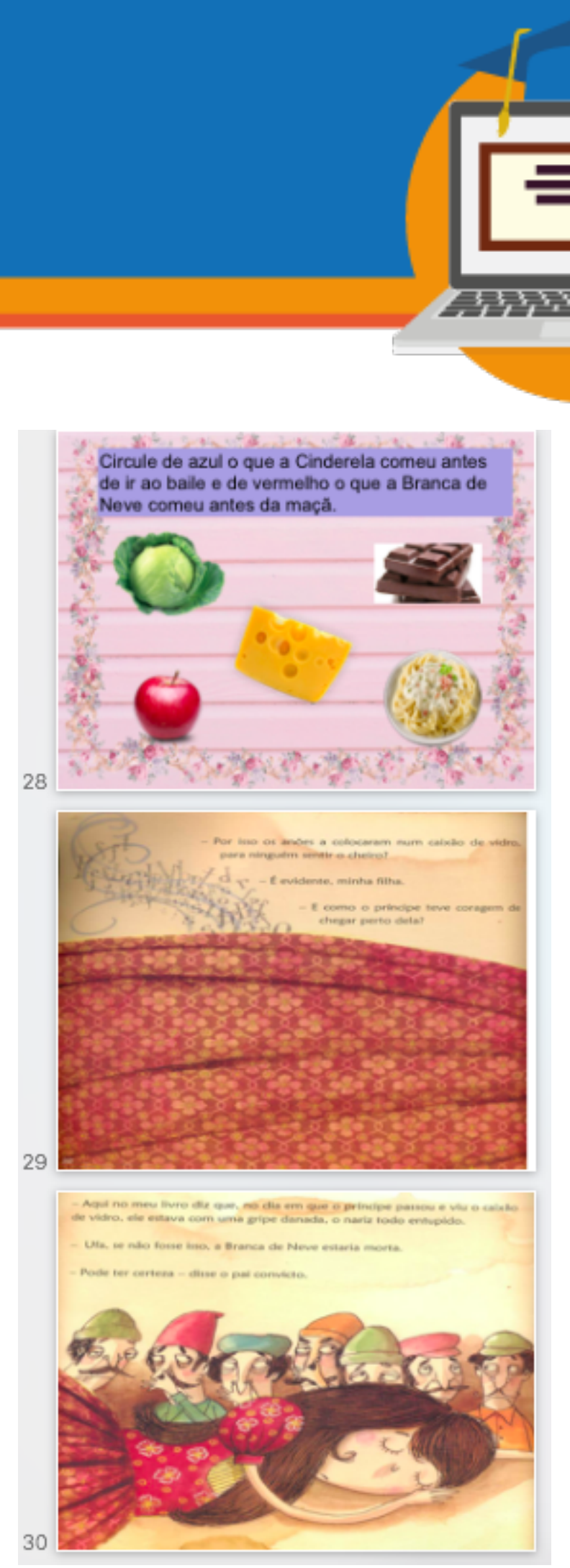

Fonte: atividade trabalhada na formação continuada.

No slide 28 foi proposto circular de azul o que a Cinderela comeu antes de ir ao baile, e de vermelho o que comeu a Branca de Neve, com o objetivo de relembrar trechos da história lida. Outra atividade possível com o slide 28 seria agregar à imagem dos alimentos, informações sobre seu valor nutricional, sobre os meios e os locais de produção onde esses alimentos são produzidos, além de receitas saudáveis com esses alimentos.

\section{SEMINÁRIO DE EDUCAÇÃO A DISTÂNCIA}

Diálogos sobre EaD e uso das TDIC na educação: regulamentação em tempos recentes 3 a 6 de novembro de 2020 - Brasília/DF - Online 

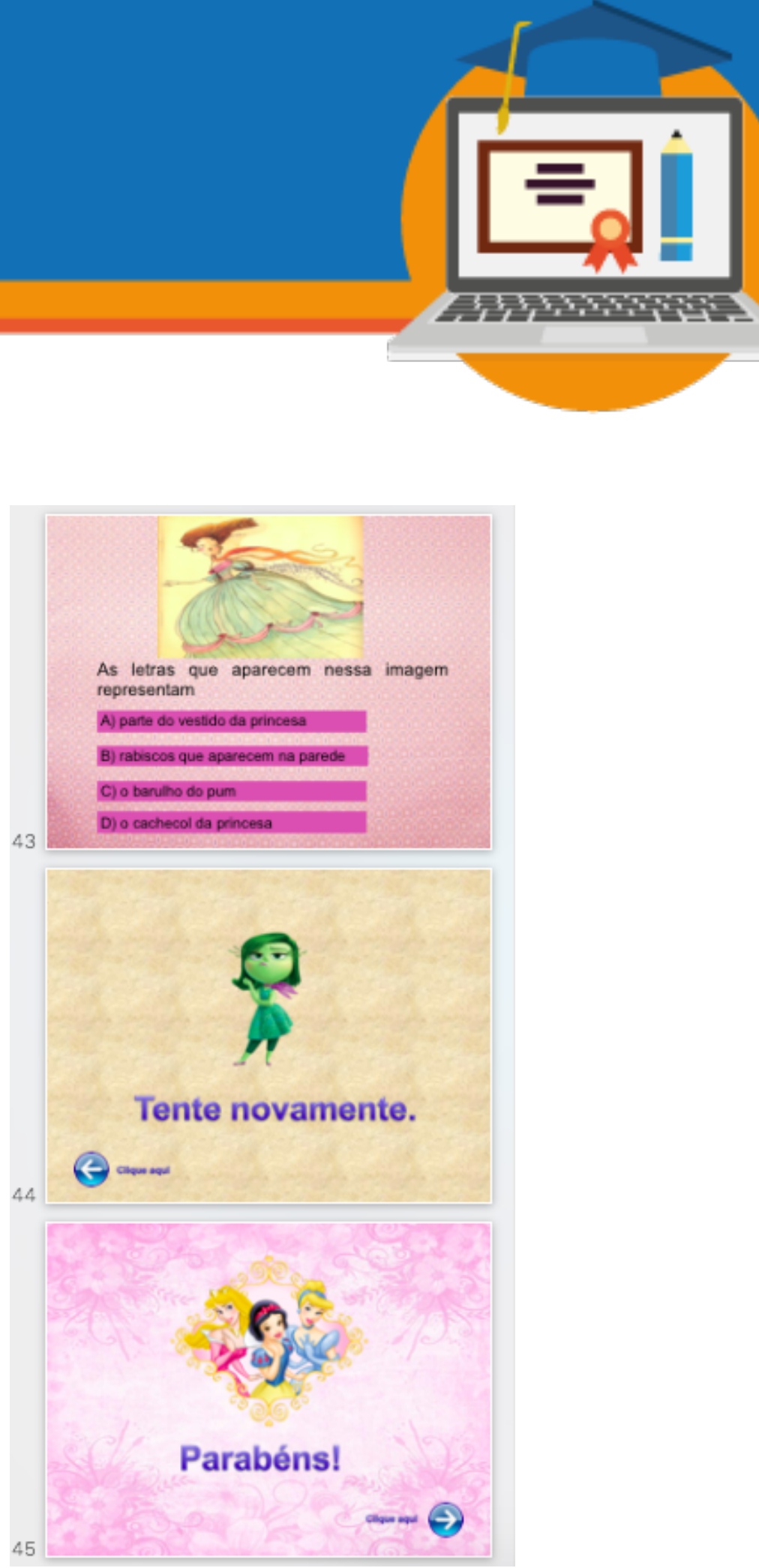

Fonte: atividade trabalhada na formação continuada.

No slide 43 é perguntado o que as letras que aparecem na imagem representam, com o objetivo de identificar qual é o elemento principal da história, onde as letras representam o pum da princesa.

Ao responder corretamente, surgia um slide com a mensagem de parabéns (slide 45) e ao responder incorretamente um slide com tente outra vez (slide 44).

\section{SEMINÁRIO DE EDUCAÇÃO A DISTÂNCIA}

Diálogos sobre EaD e uso das TDIC na educação: regulamentação em tempos recentes 3 a 6 de novembro de 2020 - Brasília/DF - Online 


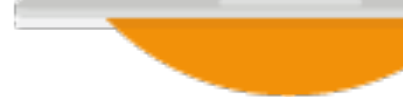

Nos exemplos mostrados acima percebemos que a leitura interativa do livro infantil proposta pelos formadores incentiva as professoras a refletirem sobre as possibilidades das TD em atividades realizadas dentro da sala de aula, ressaltando a importância da seleção prévia do material e a realização de atividades de perguntas e respostas elaboradas para um contexto específico de cada turma, levando em consideração suas preferências literárias, o conteúdo trabalhado e conhecimento das especificidades dos alunos, quer seja na antecipação das perguntas ou no interesse que as perguntas irão instigar. Além disso, podemos perceber que a interação com a lousa digital para a projeção das imagens em tamanho maior e para todos ao mesmo tempo, favorece a participação, a interação e escuta da leitura do livro digital pelas crianças, mediado pela professora em sala de aula.

Podemos perceber que a Formação continuada teve como principal finalidade orientar as professoras no uso das TD quanto as habilidades técnicas e operacionais dos letramentos digitais, como inserir caixa de texto, editar figuras e inserir hiperlink, atividades orientadas no segundo encontro da formação. Os LD mobilizados nos professores foram voltados a perspectiva educacional de letramento, a qual Magda Soares afirma que "está presente nos parâmetros curriculares nacionais, nos programas e avaliações nacionais, estaduais e municipais, designando as habilidades de leitura e de escrita de crianças, jovens ou adultos em práticas sociais que envolvem a língua escrita" (SOARES, 2010 apud SOUZA, 2016, p. 77), pois prevalece na proposição das atividades a interpretação textual e práticas de alfabetização. Além dos LD foram também mobilizados os letramentos literários nos professores relacionados a escolha e exploração de atividades de linguagens a partir de obras literárias infantis.

A cultura digital caracterizada "pela reestruturação da sociedade, oportunizada pela conectividade, emergindo transversalidade, descentralização e interatividade" (HEINSFELD e PISCHETOLA, 2017, p. 1352) demanda novas práticas pedagógicas mediadas por TD que considere as vivências dos praticantes culturais, isso agrega sentido e valor às atividades que serão propostas aos professores e professoras e em consequência reflexão quanto a presença dos artefatos tecnológicos no cotidiano.

\section{SEMINÁRIO DE EDUCAÇÃO A DISTÂNCIA}

Diálogos sobre EaD e uso das TDIC na educação: regulamentação em tempos recentes 


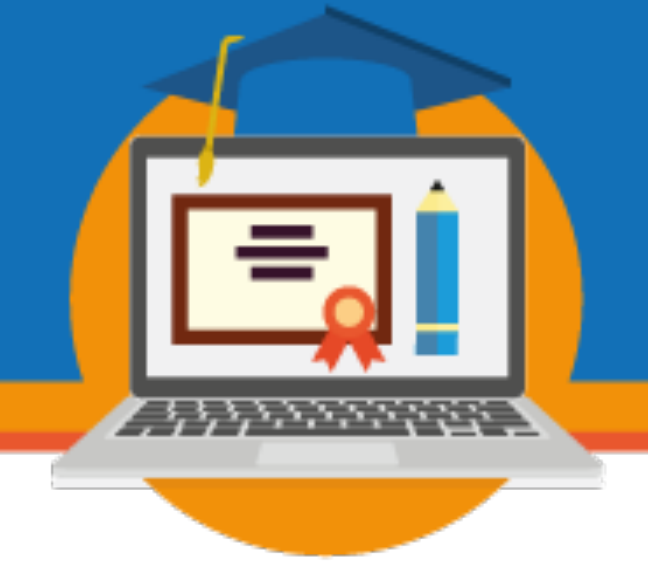

Neste sentido, Heinsfeld; Pischetola (2017) citando Naumann (2016) "propõe três aspectos da cultura digital que devem ser levados em consideração nas práticas pedagógicas com TD: (a) a possibilidade da autoria como produção própria de conhecimento; (b) a oportunidade de acesso à informação e de elaboração autoral dos conteúdos acessados, como forma de participação e protagonismo; (c) a autoria como inclusão digital" (NAUMANN, 2016 apud HEINSFELD e PISCHETOLA, 2017, p. 1359).

Em uma perspectiva mais ampla foram também mobilizados o letramento multissemiótico, definido por Rojo (2009) como "a capacidade de lidar com linguagens para além da leitura e da escrita convencionais (imagem, música, cores, sons, design, meios semióticos)" (ROJO, 2009 apud SOUZA, 2016, p. 85), percebido na exploração das imagens e da multimodalidade de linguagens e semioses nelas presentes e de certa forma na construção de narrativas pelos participantes.

Outros LD podem ter sido mobilizados nas professoras durante a FC citada, potencializando futuras reflexões nas educadoras, que entendemos estarem condicionadas as experiências e vivências prévias das professoras e nos possíveis desdobramentos que a FC pode ter provocado.

\section{Conclusões}


Percebemos nesta formação que apesar de ter uma quantidade significativa de professoras no início do curso, algumas foram desistindo ao longo das semanas, pois nem todas tinham os pré-requisitos básicos que seriam a prática com o programa Power Point ou até mesmo afinidade com o computador.

Durante os quatro encontros de execução de jogos a sequência didática não foi discutida enquanto procedimento metodológico. Assim, apesar da sequência didática constar no nome do curso, a formação limitou-se ao desenvolvimento de atividades com a utilização de “ferramentas tecnológicas" para a projeção na lousa digital. Todos os conteúdos propostos para serem desenvolvidos no programa PowerPoint foram alcançados até o final do curso, entretanto, muitas professoras tiveram dificuldades de compreensão de termos e localização de atalhos por conta do distanciamento que relataram ter com o uso de TD, incluindo o computador.

Compreendemos que há outros LD possíveis que poderiam ter sido mobilizados nas professoras durante a FC, sendo eles: letramentos informacional, multimidiático, comunicacional e linguístico, com atividades de inserção de outras mídias com possibilidade de contar a história (filme, história em quadrinho, desenho, podcast ${ }^{\natural}$ ). Localizar informações complementares às histórias em sites de busca, produção de noticias como disparadoras para trabalhar com as Fakenews, utilização de app de navegação, localizar outras versões das histórias na internet, recontar a história em vídeo, criar memes com os personagens da história, fazer um tutorial para compartilhar no YouTube, dentre outras possibilidades ao desenvolvimentos de novos LD.

Portanto, compreendemos que a FC pode promover reflexões quanto as práticas pedagógicas mediadas pelas TD e potencializar os LD dos professores e ampliar o olhar para além das habilidades funcionais para o uso de TD no contexto educacional, considerando as novas relações com a informação e o conhecimento reorganizadas pela cultura digital.

${ }^{9}$ é um arquivo digital de áudio transmitido através da internet, cujo conteúdo pode ser variado, geralmente com o propósito de transmitir informações. 


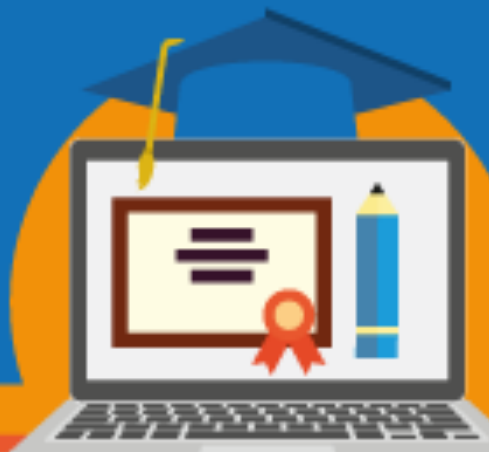

\section{Referências}

III SEMINÁRIO DE EDUCAÇÃO A DISTÂNCIA

Diálogos sobre EaD e uso das TDIC na educação: regulamentação em tempos recentes

3 a 6 de novembro de 2020 - Brasília/DF - Online 


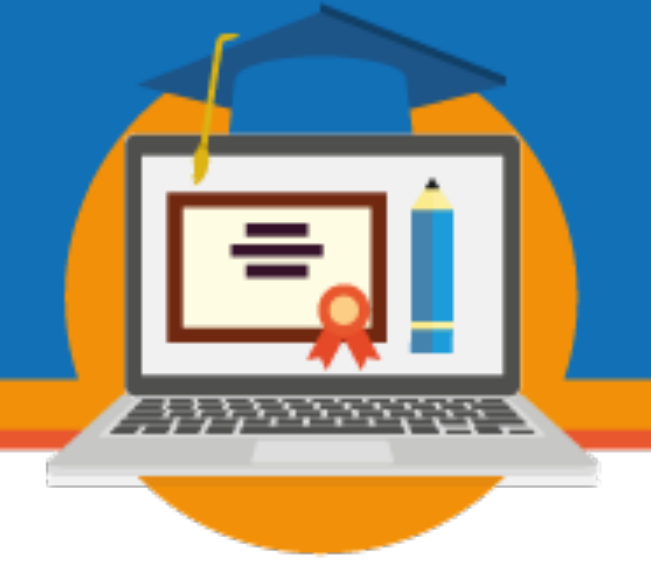

COELHO, Novaes Nelly. Literatura Infantil. 1. Ed. São Paulo: Moderna, 2000.

HEINSFELD Bruna Damiana. PISCHETOLA Magda. Cultura digital e educação, uma leitura dos Estudos Culturais sobre os desafios da contemporaneidade. RIAEE - Revista IberoAmericana de Estudos em Educação, v. 12, n. esp. 2, p. 1349-1371, ago./2017. E-ISSN: 19825587. Disponível em: http://dx.doi.org/10.21723/riaee.v12.n.esp.2.10301

LUCENA, Simone. Culturas digitais e tecnologias móveis na educação. Educar em Revista. Curitiba, Brasil, n. 59, p. 277-290, jan./mar. 2016.

MILITÃO, A. N.; LEITE, Y. U. F. A Historicidade do Conceito de Formação Continuada: uma análise da visão de Paulo Freire sobre a formação permanente. In: VII Congresso Brasileiro de História da Educação, 2013, Cuiabá. Anais do VII Congresso Brasileiro de História da Educação. Cuiabá - MT: SBHE, 2013. v. 1.p. 1-15.

MATOS, Nathalia Cristina et al. A Formação Continuada de Professores da Educação Básica: uma Revisão Sistemática. Cadernos de Pesquisa: Pensamento Educacional, Curitiba, v. 11, n. 28, p.45-64 maio/ago. 2016. Disponível em: http://www.utp.br/cadernos_de_pesquisa.

SANTAELLA, Lúcia. A Ecologia Pluralista da Comunicação. Conectividade, mobilidade, ubiquidade. São Paulo: Paulus, 2010.

SILVA, Danilo Garcia da; ALONSO, Katia Morosov. Formação on-line e praticantes culturais: elementos sócio-históricos em contextos de formação na cultura digital. Momento - Diálogos em Educação, v. 27, n. 1, p. 108-127, maio 2018. ISSN 2316-3100. Disponível em: https://periodicos.furg.br/momento/article/view/7794. Acesso em: 04 jan. 2020. 


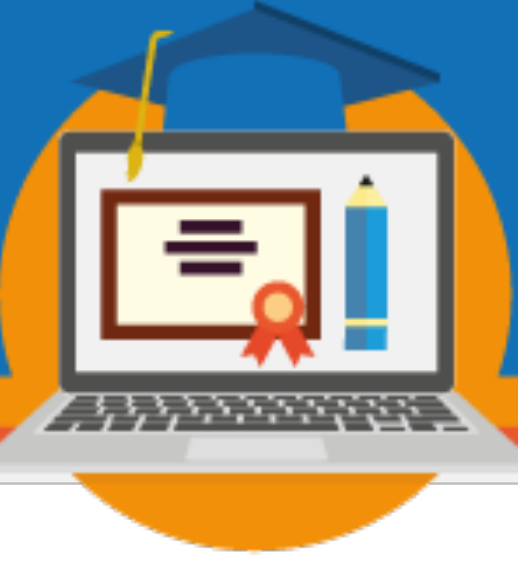

SOUZA, Terezinha Fernandes Martins de. Ondas em ressonância: letramentos digitais de estudantes na Universidade Aberta de Portugal. Tese de Doutorado. Ed.UFSC, 2016.

VYGOTSKY. A formação social da mente: o desenvolvimento dos processos psicológicos superiores. Organizadores Michael Cole et al. Tradução José Cipolla Neto, Luís Silveira Menna Barreto, Solange Castro Afeche. 7. ed. São Paulo: Martins Fontes, 2007.

ZABALA, Antoni. A prática educativa: como ensinar. 1. Ed. Porto Alegre: Artmed, 1998. 